\title{
Electronic Mechanisms of Intra and Intermolecular J Couplings in Systems with $\mathrm{C}-\mathrm{H} \cdots \mathrm{O}$ Interactions
}

\author{
Claudia G. Giribet ${ }^{+}$, Martin C. Ruiz de Azua ${ }^{+*}$, Celia V. Vizioli and Claudio N. Cavasotto ${ }^{\#}$ \\ Departamento de Física, Facultad de Ciencias Exactas y Naturales, Universidad de Buenos Aires, \\ Ciudad Universitaria Pab. 1, (1428) Buenos Aires, Argentina. \\ ${ }^{+}$Member of Carrera del Investigador, CONICET. \\ *Author to whom correspondence should be addressed. Email: azua@df.uba.ar \\ \#Present address: Molsoft LLC, 3366 N Torrey Pines Ct., Ste 300, La Jolla, CA 92037, USA.
}

Received: 15 October 2002 / Accepted: 19 November 2002 / Published: 4 April 2003

\begin{abstract}
Correlation effects on the change of ${ }^{1} \mathrm{~J}(\mathrm{CH})$ couplings in model systems I:NCH.... $\mathrm{H}_{2} \mathrm{O}$ and II: $\mathrm{CH}_{4} \ldots \mathrm{H}_{2} \mathrm{O}$ as a function of the $\mathrm{H} . . . \mathrm{O}$ distance are discussed. RPA and SOPPA results follow a similar trend in system II. In system I RPA values decrease monotonously as the H...O distance decreases, while SOPPA ones exhibit flat maximum near equilibrium. Such different behavior is ascribed to the $\pi$-transmitted component. Intermolecular couplings at the equilibrium geometry of I are analyzed by means of the CLOPPA approach. The larger absolute value of ${ }^{2 \mathrm{~h}} \mathrm{~J}(\mathrm{CO})$ compared to ${ }^{1 \mathrm{~h}} \mathrm{~J}(\mathrm{HO})$ is found to arise from contributions involving a vacant LMO localized in the C-H...O moiety.
\end{abstract}

Keywords: C-H...O interactions, NMR couplings, Correlation effects, Intermolecular couplings, Localized molecular orbitals.

\section{Introduction}

Specific interactions of type X-H...Y between proximate moieties can be important to determine conformational structures as well as stabilization energies in molecules, especially biomolecules, in intermolecular complexes or molecular solids. A sound knowledge on the relation between J couplings of the $\mathrm{X}-\mathrm{H}$...Y fragment and structural parameters can be a valuable tool in structure determination. Great effort has been devoted to this subject in recent years [1-10]. In particular, it has been recognized that $\mathrm{C}-\mathrm{H}$... X interactions depend strongly on the kind of molecular moiety to which the $\mathrm{C}-\mathrm{H}$ bond and 
$\mathrm{X}$ atom belong to $[11,12]$. This is certainly due to the fact that different competitive effects are present and the dominant one depends on the molecular environment. In model systems I: $\mathrm{NCH}_{2} . \mathrm{OH}_{2}$ and II: $\mathrm{CH}_{4} \ldots \mathrm{OH}_{2}$ the theoretical analysis of stabilization energy, geometric changes of the $\mathrm{C}-\mathrm{H}$ bond and ${ }^{1} \mathrm{~J}(\mathrm{CH})$ couplings [13] showed that the C-H...O interaction has different characteristics in each case: in system I the stabilization energy is larger and the $\mathrm{C}-\mathrm{H}$ bond length increases; in system II the equilibrium $\mathrm{H}$...O distance is much larger, there is a shallow energy minimum and the $\mathrm{C}-\mathrm{H}$ distance is hardly affected.

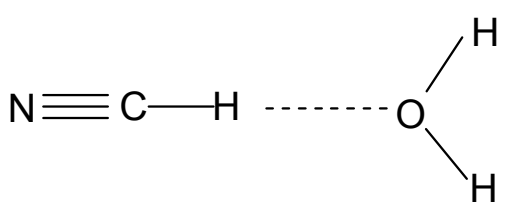

I

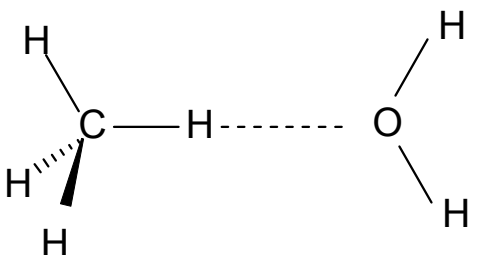

II

The possibility of using NMR parameters as probes to identify the kind of dominant specific interaction $\mathrm{C}-\mathrm{H}$... $\mathrm{O}$ in different situations was investigated at the ab initio level for both ${ }^{1} \mathrm{~J}(\mathrm{CH})$ couplings and $\mathrm{C}, \mathrm{H}$ and $\mathrm{O}$ magnetic shielding constants $[13,14,15]$. In previous work, the change in $\mathrm{J}$ couplings was analyzed at the TDA [14] and CHF [13] levels since it was assumed that, even though it is well known that ${ }^{1} \mathrm{~J}(\mathrm{CH})$ couplings are very sensitive to correlation effects, the changes in those couplings in the presence of the specific $\mathrm{C}-\mathrm{H}$...O interaction could probably be well reproduced at the uncorrelated level. More recently, Pecul et al. [16] have analyzed the intermolecular couplings ${ }^{1 \mathrm{~h}} \mathrm{~J}$ and ${ }^{2 h} \mathrm{~J}$ in $\mathrm{X}-\mathrm{H} . . . \mathrm{O}$ hydrogen bonded complexes, including the case $\mathrm{C}_{2} \mathrm{H}_{2} \ldots \mathrm{OH}_{2}$.

Theoretical decomposition of molecular properties like stabilization energy and/or NMR parameters in contributions from molecular fragments is an interesting tool to identify the kind of dominant effect in different cases. The aim of the present work is to deepen the understanding of electronic mechanisms operating in $\mathrm{C}-\mathrm{H}$...O interactions and their effect on both intramolecular ${ }^{1} \mathrm{~J}(\mathrm{CH})$ couplings as well as intermolecular J couplings. Calculations were carried out at both the CHF and SOPPA levels of approximation in order to assess the importance of correlation effects. In line with previous work [13], systems I: $\mathrm{NCH} \ldots \mathrm{H}_{2} \mathrm{O}$ and II: $\mathrm{CH}_{4} \ldots \mathrm{H}_{2} \mathrm{O}$ were chosen as model compounds. System I exemplifies the case of a $\mathrm{C}-\mathrm{H}$ bond belonging to a highly polar fragment with a highly polarizable $\pi$ system where a lengthening of the $\mathrm{C}-\mathrm{H}$ bond occurs as a consequence of interactions with the $\mathrm{H}_{2} \mathrm{O}$ molecule. In system II the $\mathrm{C}-\mathrm{H}$ bond belongs to a non-polar system with no neighbouring $\pi$ electronic system, where the $\mathrm{C}-\mathrm{H}$ bond length is hardly affected for intermolecular distances close to equilibrium. The geometrical effect is explicitly separated in the calculation of $\mathrm{J}$ couplings. Correlation effects, which are shown to be of major importance, are related to the polarizability of molecular fragments by means of the CLOPPA-IPPP decomposition of the polarizability tensor [17]. Results obtained complement previous work with important new qualitative features. 


\section{Method of Calculation}

Within the polarization propagator (PP) formalism [18], any component of the indirect nuclear spinspin coupling between nuclei A and B can be expressed as [19]:

$$
J(A B)=\sum_{i a, j b} V_{i a}(A) P_{i a, j b} V_{j b}(B)
$$

where $i, j \ldots(a, b \ldots)$ stand for occupied (vacant) molecular orbitals (MOs) of a Hartree-Fock reference state. $V_{\mathrm{ia}}(\mathrm{A})$ stands for the matrix element of the perturbative interaction between MOs i,a centered at nucleus A. For the Fermi contact (FC) interaction it is given by:

$$
V_{i a}(A)=k\left\langle i \delta\left(r-R_{A}\right) b\right\rangle
$$

where $\mathrm{k}$ is a constant containing, among others, the gyromagnetic factor of nucleus $\mathrm{A} . \mathrm{P}_{\mathrm{i} a \mathrm{j} \mathrm{b}}$ is the PP matrix element connecting "virtual excitations" i,a and j,b. The coupling constant J(AB) in eq.(1) can be re-expressed in terms of localized MOs (LMOs) by applying to the PP matrix elements and to the interaction matrix elements the corresponding transformation from canonical HF MOs to occupied and vacant LMOs [20]. A four-indices term involving two virtual excitations $i \rightarrow a$ and $j \rightarrow b$ is defined as:

$$
J_{i a, j b}= \begin{cases}\left(V_{i a}(A) V_{j b}(B)+V_{j b}(A) V_{i a}(B)\right) P_{i a, j b} & i a \neq j b \\ V_{i a}(A) V_{i a}(B) P_{i a, i a} & i a=j b\end{cases}
$$

and is called a four-indices coupling pathway. Within ab initio calculations and Engelmann's localization technique [21] applied in this work, there are several vacant LMOs within a given local fragment. If the indices $a$ and $b$ identify local fragments it is useful to define the corresponding coupling pathway as:

$$
J_{i a, j b}=\sum_{\substack{\alpha w i t h i i^{\prime} a^{\prime} \\ \beta w i t h i n ' b^{\prime}}} J_{i \beta}
$$

where $\alpha(\beta)$ identify vacant LMOs of the a(b) type.

For a given pair of occupied LMOs i,j a two indices coupling pathway can be defined by summing over the whole set of vacant MOs:

$$
J_{i, j}=\sum_{a, b} J_{i a, j b}
$$


Two and four-indices coupling pathways can be useful tools to identify transmission mechanisms of J couplings in terms of local fragments of the electronic distribution. This is the aim of the CLOPPA (Contributions from LMOs within the PP Approach) method [20]. On one hand, "perturbators" $\mathrm{V}_{\text {ia }}$ depend on the perturbative interaction under study and reflect the strength of the $\mathrm{i} \rightarrow \mathrm{a}$ virtual excitation. On the other hand, PP matrix elements are perturbation independent: they reflect to what extent two virtual excitations are connected by interactions within the molecular system. The PP in eq.(1) may be evaluated at different levels of approximation: RPA, SOPPA [22,23] etc. In the present work CLOPPA analysis are carried out at the RPA level.

The localization technique used in this work is Engelmann's [21], applied in an iterative way. In order to obtain LMOs a given local fragment is defined by a subset of atomic orbitals (AOs). LMOs within the fragment are obtained as combinations of MOs with maximum orthogonal projection within the local fragment thus defined with the constraint that LMOs are orthogonal to each other. This procedure is applied separately to occupied and vacant MOs. Occupied LMOs can be classified as atomic inner shells $\mathrm{s}(\mathrm{X})$, bonding orbitals $\mathrm{X}-\mathrm{Y}$ and atomic lone pairs $\mathrm{lp}(\mathrm{X})$.

Localization of vacant MOs is a difficult task, since the number and type of vacant MOs depend on the basis set. The following procedure was adopted in the present work in order to obtain vacant LMOs in system I. First, one center vacant LMOs were defined as those having maximum projection on the set of AOs centered at a given atomic nucleus $\mathrm{X}$ and negligibly small projection on the set of AOs of the other atomic centers. They are identified as $s(X) *$ when they are of s-type and $\operatorname{lp}(X) *$ when they are of s-p-d or pure $p$ type. Secondly, two centers vacant LMOs were defined following a similar procedure. The two-center atomic projectors were defined between directly bonded atoms where formation of antibonding orbitals is expected. They are identified as X-Y*. As a result, there were only two vacant MOs which could not be localized in this way. These are three-center MOs localized in the hydrogen bond region C-H...O. One of them is a combination of $d_{x y}$ type AOs. As these AOs have zero amplitude at the $\mathrm{C}, \mathrm{H}$ and $\mathrm{O}$ positions, this LMO does not enter coupling pathways of the $\mathrm{FC}$ interaction. Only one three center C-H...O* LMO is left which is expected to play an important role in transmission mechanisms of intermolecular couplings.

For both systems I and II, geometry optimizations were carried out for selected fixed O...H distances including, of course, that of equilibrium of each complex. Geometry optimizations were carried out at the MP2 level with the GAUSSIAN program [24]. The equilibrium H...O distance is $2.110 \AA$ for system I and $2.880 \AA$ for system II. Calculations of J couplings and of the molecular polarizability tensor were carried out at both RPA and SOPPA levels in order to assess the importance of correlation effects. To this end, the SYSMO [25-27] and DALTON [28] programs were used. CLOPPA decomposition of $\mathrm{J}$ couplings was carried out at the RPA level with a modified version of the SYSMO program. The AO basis set used is Van Duijneveldt's (13s7p1d,8s1p)-[11s5p1d,5s1p] [29]. Basis set superposition errors were taken into account by the counterpoise method to compare molecular parameters of the complex and isolated systems. The electric field effect of the $\mathrm{H}_{2} \mathrm{O}$ 
molecule on $\mathrm{NCH}$ or $\mathrm{CH}_{4}$ was obtained by replacing the $\mathrm{H}_{2} \mathrm{O}$ molecule by three point charges at the sites of the $\mathrm{O}$ and $\mathrm{H}$ nuclei. The values of the point charges were those yielding the correct dipole moment of the $\mathrm{H}_{2} \mathrm{O}$ molecule at each $\mathrm{H}$... O distance.

\section{Results and Discussion}

\section{${ }^{1} \mathrm{~J}(\mathrm{CH})$ Couplings}

In figure 1 , the change $\Delta \mathrm{J}$ in ${ }^{1} \mathrm{~J}(\mathrm{CH})$ as a function of the $\mathrm{H}$...O distance for system I is presented. It corresponds to the difference between the ${ }^{1} \mathrm{~J}(\mathrm{CH})$ value for the complex at the optimized geometry and that for the isolated NCH molecule. This change will be identified by $\Delta \mathrm{J}^{\mathrm{C}}$. The electric field effect is shown in the same figure. It corresponds to the difference between the ${ }^{1} \mathrm{~J}(\mathrm{CH})$ value calculated in the presence of the $\mathrm{H}_{2} \mathrm{O}$ electric field for each $\mathrm{H}$...O distance considering the optimized geometry of the $\mathrm{NCH}$ molecule in the complex and the ${ }^{1} \mathrm{~J}(\mathrm{CH})$ value of the isolated $\mathrm{NCH}$ molecule. This change will be identified as $\Delta \mathrm{J}^{\mathrm{E}}$. Results in figure 1 were obtained at both RPA and SOPPA levels for the Fermi contact (FC) term of the coupling, as it has been shown previously that other terms are unimportant to define the trend of ${ }^{1} \mathrm{~J}(\mathrm{CH})$ couplings in C-H...O interactions [13]. In figure 2 the same $\Delta \mathrm{J}^{\mathrm{C}}$ and $\Delta \mathrm{J}^{\mathrm{E}}$ changes are shown for the $\mathrm{CH}_{4}$ molecule in system II.

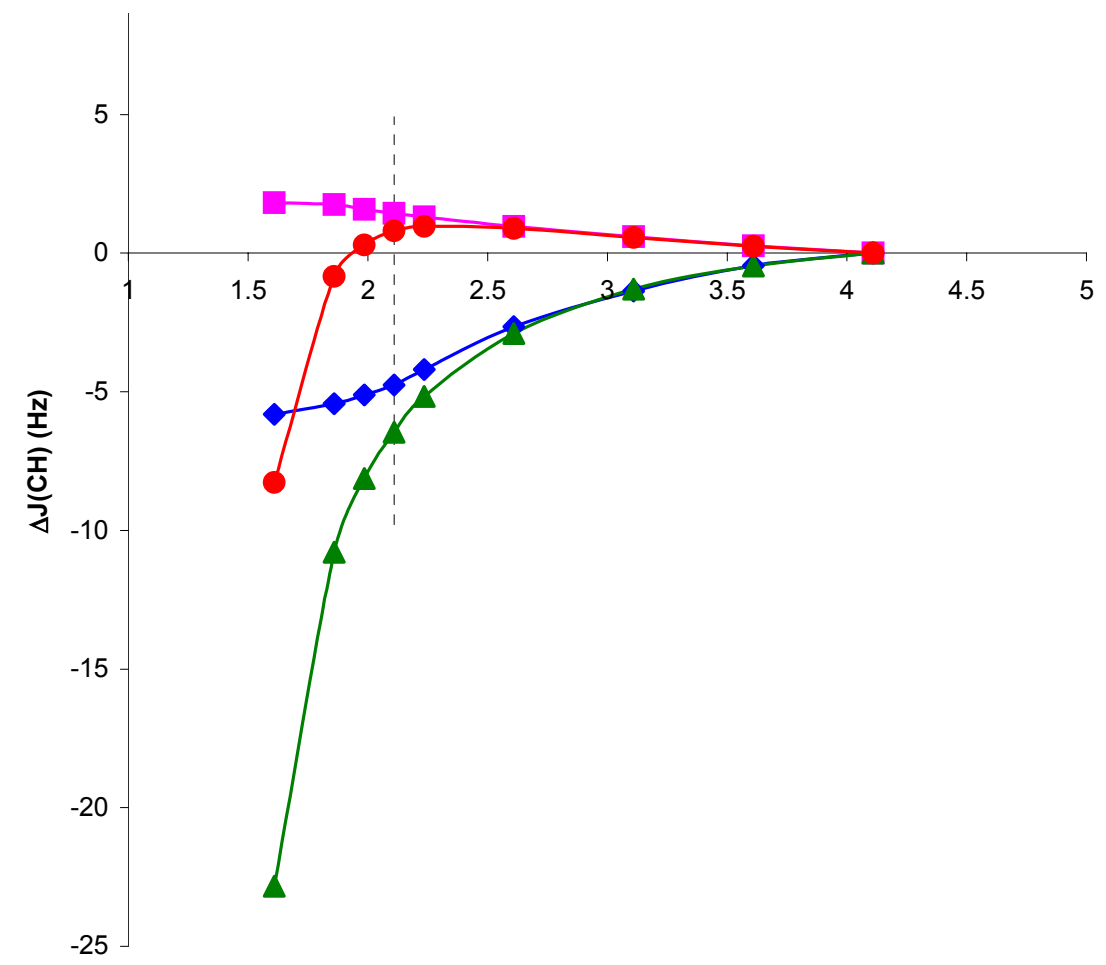

$\mathbf{r}(\mathbf{H} \ldots$...) $(\AA)$

Figure 1. Change in ${ }^{1} \mathrm{~J}(\mathrm{CH})$ for the $\mathrm{NCH} . . . \mathrm{OH}_{2}$ complex, $\Delta \mathrm{J}^{\mathrm{C}}$, and in the presence of the $\mathrm{H}_{2} \mathrm{O}$ electric field, $\Delta \mathrm{J}^{\mathrm{E}}$, with respect to ${ }^{1} \mathrm{~J}(\mathrm{CH})$ for the isolated $\mathrm{NCH}$ molecule, as a function of the $\mathrm{H} . . . \mathrm{O}$ distance,

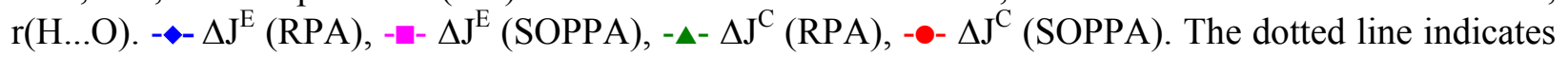
the equilibrium distance. 


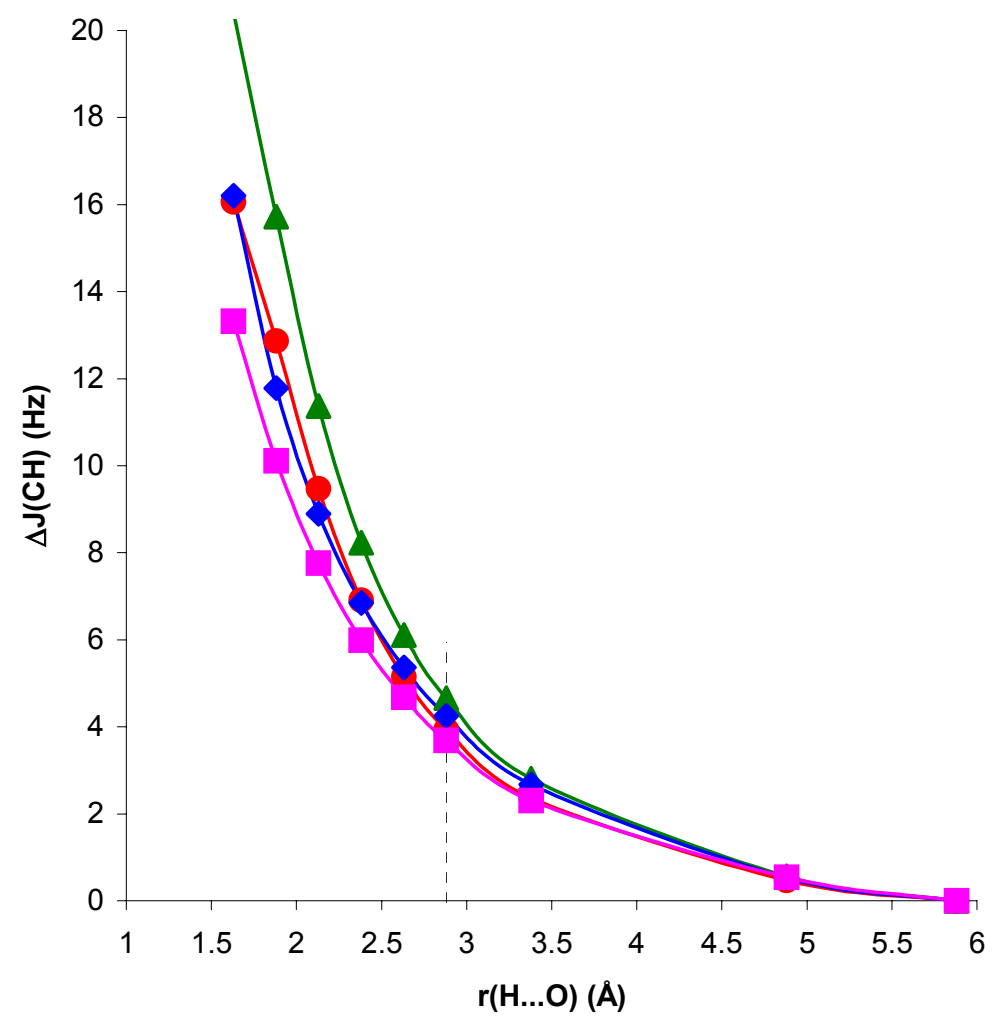

Figure 2. Change in ${ }^{1} \mathrm{~J}(\mathrm{CH})$ for the $\mathrm{CH}_{4} \ldots \mathrm{OH}_{2}$ complex, $\Delta \mathrm{J}^{\mathrm{C}}$, and in the presence of the $\mathrm{H}_{2} \mathrm{O}$ electric field, $\Delta \mathrm{J}^{\mathrm{E}}$, with respect to ${ }^{1} \mathrm{~J}(\mathrm{CH})$ for the isolated $\mathrm{CH}_{4}$ molecule, as a function of the $\mathrm{H}$...O distance,

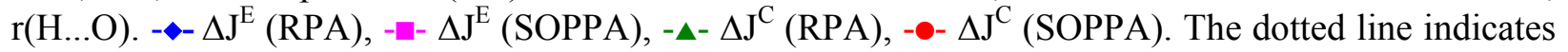
the equilibrium distance.

Comparison of RPA and SOPPA results in figures 1 and 2 shows the importance of correlation effects in defining $\Delta \mathrm{J}^{\mathrm{C}}$ and $\Delta \mathrm{J}^{\mathrm{E}}$ in systems I and II. For system II, $\Delta \mathrm{J}^{\mathrm{C}}$ and $\Delta \mathrm{J}^{\mathrm{E}}$ behave similarly when calculated at the RPA and SOPPA levels. SOPPA values reflect a smoother change in ${ }^{1} \mathrm{~J}(\mathrm{CH})$ than RPA ones as the H...O distance decreases. However, the increase obtained for H...O distances close to equilibrium is significant and measurable. Results for system I exhibit a quite different behaviour. The qualitative trend of ${ }^{1} \mathrm{~J}(\mathrm{CH})$ is dramatically changed when correlated values are considered for both $\Delta \mathrm{J}^{\mathrm{C}}$ and $\Delta \mathrm{J}^{\mathrm{E}}$. The competition of two different effects seems to define the trend observed for SOPPA values. For H...O distances larger than equilibrium a smooth increase in ${ }^{1} \mathrm{~J}(\mathrm{CH})$ for decreasing $\mathrm{H}$...O distances is observed. This trend is opposite to that obtained at both RPA and TDA levels $[13,15]$. For distances shorter than equilibrium an effect yielding a decrease of ${ }^{1} \mathrm{~J}(\mathrm{CH})$ seems to dominate, and $\Delta \mathrm{J}^{\mathrm{C}}$ and $\Delta \mathrm{J}^{\mathrm{E}}$ follow different trends. This is in line with previous findings for the magnetic shielding constants in systems I and II [14]. As a result, for distances close to equilibrium the two effects nearly cancel each other and $\Delta \mathrm{J}^{\mathrm{C}}$ and $\Delta \mathrm{J}^{\mathrm{E}}$ exhibit small positive values. This result is in line with that found by Pecul et al. [16] for the $\mathrm{C}_{2} \mathrm{H}_{2} \ldots \mathrm{H}_{2} \mathrm{O}$ complex. Such small change can easily be hidden by other effects in a larger molecular environment. Therefore, SOPPA results suggest that ${ }^{1} \mathrm{~J}(\mathrm{CH})$ can be a 
probe for the presence of C-H...O interactions in systems of type II, but only minor changes can be expected in systems of type I at distances close to or larger than equilibrium.

In order to deepen the previous analysis it is interesting to see the role played by geometric changes in defining $\Delta \mathrm{J}^{\mathrm{C}}$ and $\Delta \mathrm{J}^{\mathrm{E}}$. To this end ${ }^{1} \mathrm{~J}(\mathrm{CH})$ was calculated for the isolated molecules $\mathrm{NCH}$ and $\mathrm{CH}_{4}$ at the geometry they adopt upon complexation for every H...O distance. The difference between this value and that of the isolated molecule at its equilibrium geometry is identified as $\Delta J^{G}$ and it is plotted as a function of the H...O distance in figures 3 and 4 for systems I and II respectively, at both RPA and SOPPA levels. The differences $\Delta \mathrm{J}^{\mathrm{CG}}=\Delta \mathrm{J}^{\mathrm{C}}-\Delta \mathrm{J}^{\mathrm{G}}$ and $\Delta \mathrm{J}^{\mathrm{EG}}=\Delta \mathrm{J}^{\mathrm{E}}-\Delta \mathrm{J}^{\mathrm{G}}$ reflect the complex and electric field changes in ${ }^{1} \mathrm{~J}(\mathrm{CH})$ at every fixed optimized geometry, respectively. The corresponding values are plotted in figures 5 and 6 for systems I and II, respectively.

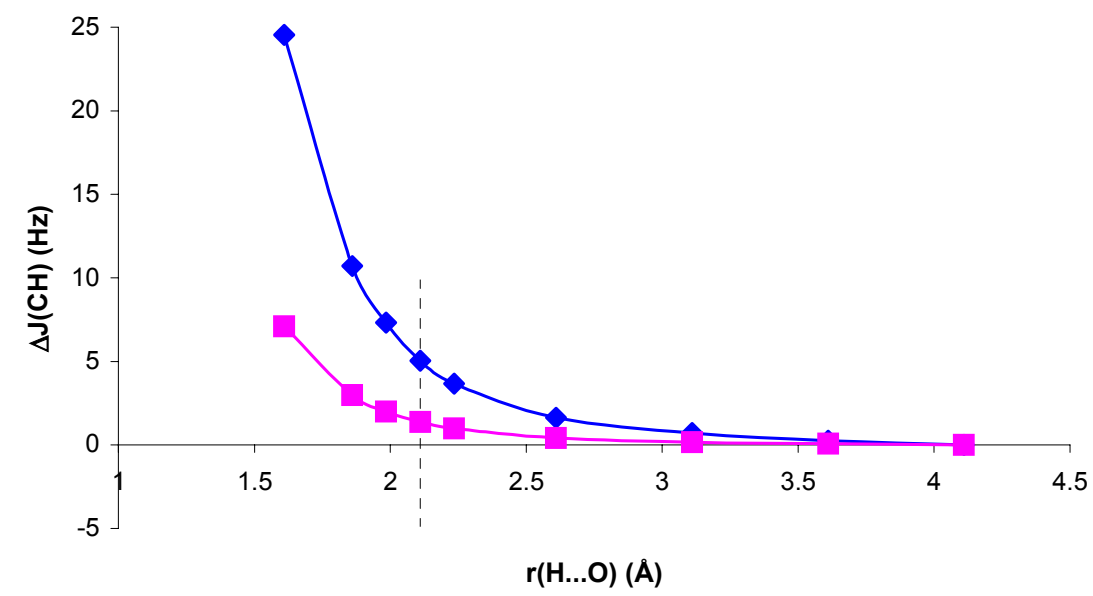

Figure 3. Geometric change in ${ }^{1} \mathrm{~J}(\mathrm{CH})$ for the $\mathrm{NCH}$ molecule with the complex geometry, $\Delta \mathrm{J}^{\mathrm{G}}$, with respect to ${ }^{1} \mathrm{~J}(\mathrm{CH})$ for the isolated $\mathrm{NCH}$ molecule, as a function of the $\mathrm{H}$...O distance, $\mathrm{r}(\mathrm{H} \ldots \mathrm{O}) .-\diamond-\Delta \mathrm{J}^{\mathrm{G}}$ (RPA), - $-\Delta \mathrm{J}^{\mathrm{G}}$ (SOPPA). The dotted line indicates the equilibrium distance.

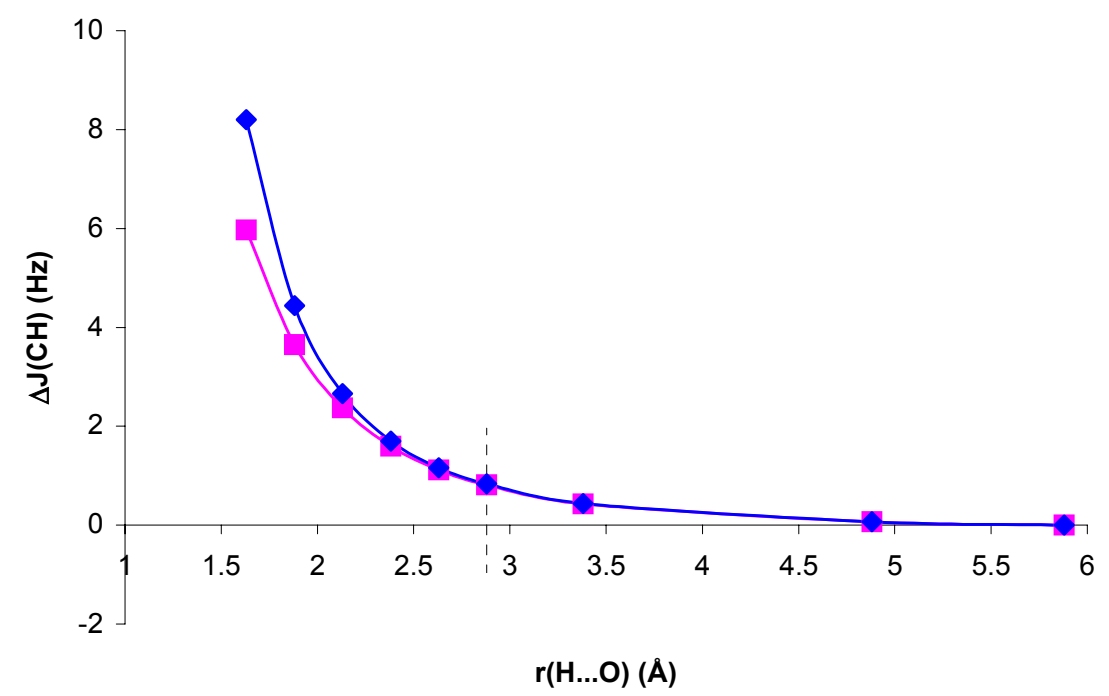

Figure 4. Geometric change in ${ }^{1} \mathrm{~J}(\mathrm{CH})$ for the $\mathrm{CH}_{4}$ molecule with the complex geometry, $\Delta \mathrm{J}^{\mathrm{G}}$, with respect to ${ }^{1} \mathrm{~J}(\mathrm{CH})$ for the isolated $\mathrm{CH}_{4}$ molecule, as a function of the H...O distance, $r(\mathrm{H} \ldots \mathrm{O}) .-\diamond-\Delta \mathrm{J}^{\mathrm{G}}$ (RPA), - $-\Delta \mathrm{J}^{\mathrm{G}}$ (SOPPA). The dotted line indicates the equilibrium distance. 


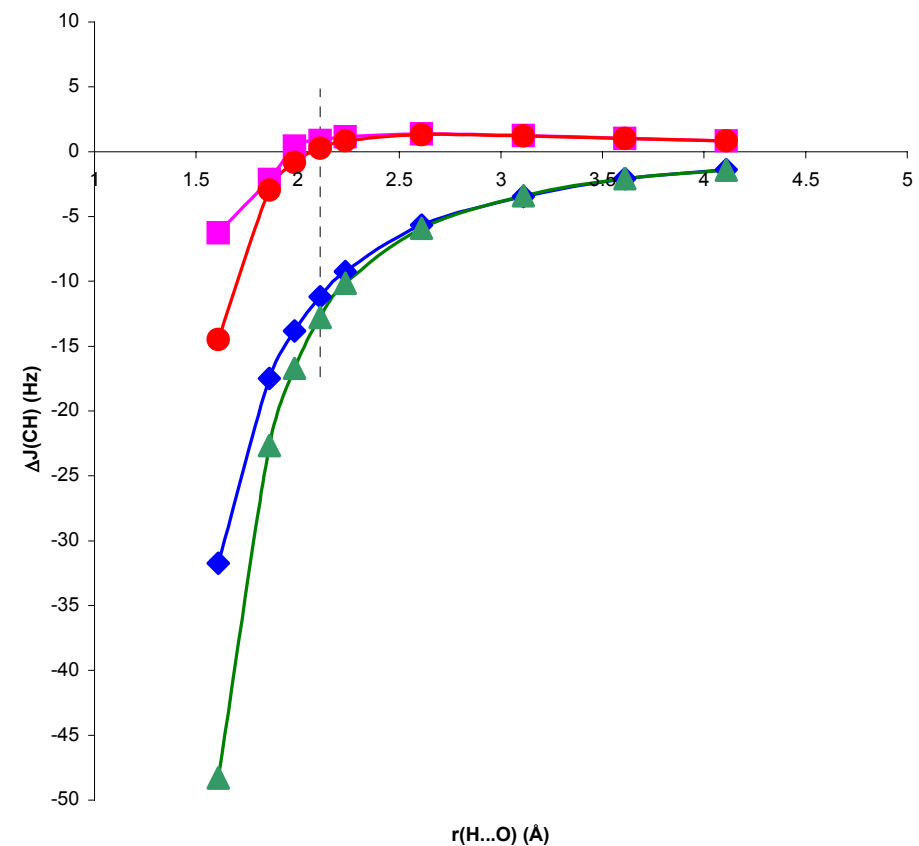

Figure 5. Complex and electric field changes in ${ }^{1} \mathrm{~J}(\mathrm{CH})$ for the $\mathrm{NCH} . . \mathrm{OH}_{2}$ complex, $\Delta \mathrm{J}^{\mathrm{CG}}$ and $\Delta \mathrm{J}^{\mathrm{EG}}$ respectively, at every optimized geometry, with respect to ${ }^{1} \mathrm{~J}(\mathrm{CH})$ for the isolated $\mathrm{NCH}$ molecule, as a

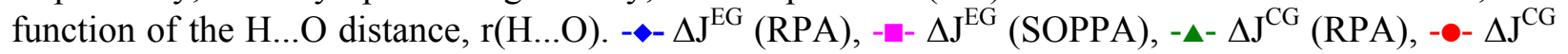
(SOPPA). The dotted line indicates the equilibrium distance.

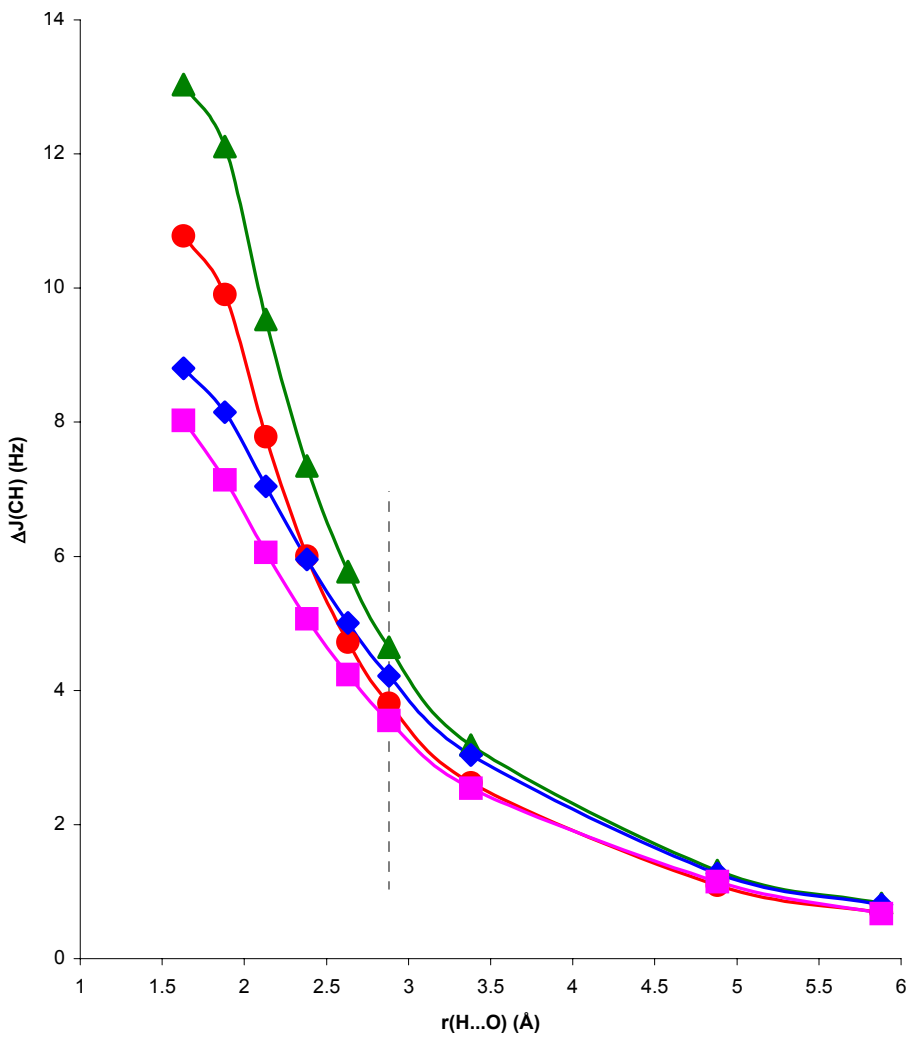

Figure 6. Complex and electric field changes in ${ }^{1} \mathrm{~J}(\mathrm{CH})$ for the $\mathrm{CH}_{4} \ldots \mathrm{OH}_{2}$ complex, $\Delta \mathrm{J}^{\mathrm{CG}}$ and $\Delta \mathrm{J}^{\mathrm{EG}}$ rspectively, at every optimized geometry, with respect to ${ }^{1} \mathrm{~J}(\mathrm{CH})$ for the isolated $\mathrm{CH}_{4}$ molecule, as a function of the H...O distance, $\mathrm{r}(\mathrm{H} . . . \mathrm{O}) .-\Delta-\Delta \mathrm{J}^{\mathrm{EG}}$ (RPA), - - $\Delta \mathrm{J}^{\mathrm{EG}}$ (SOPPA), - $\Delta-\Delta \mathrm{J}^{\mathrm{CG}}$ (RPA), - $\triangle \mathrm{J}^{\mathrm{CG}}$ (SOPPA). The dotted line indicates the equilibrium distance. 
In both cases, for distances larger than and close to equilibrium SOPPA values of $\Delta \mathrm{J}^{\mathrm{G}}$ are very small and $\Delta \mathrm{J}^{\mathrm{CG}}, \Delta \mathrm{J}^{\mathrm{EG}}$ follow closely the trend of $\Delta \mathrm{J}^{\mathrm{C}}, \Delta \mathrm{J}^{\mathrm{E}}$. For H...O distances shorter than equilibrium, in system II $\Delta \mathrm{J}^{\mathrm{G}}$ is positive, i.e. the geometric contribution enhances the trend of $\Delta \mathrm{J}^{\mathrm{CG}}$ and $\Delta \mathrm{J}^{\mathrm{EG}}$. In system I the opposite occurs: $\Delta \mathrm{J}^{\mathrm{G}}$ is positive but $\Delta \mathrm{J}^{\mathrm{CG}}$ and $\Delta \mathrm{J}^{\mathrm{EG}}$ are negative. The overall trend, however, is defined by this last contribution. Therefore, the role played by polarization of the electronic system in the presence of the $\mathrm{H}_{2} \mathrm{O}$ molecule is essential to define the trend of the ${ }^{1} \mathrm{~J}(\mathrm{CH})$ coupling in system I for distances shorter than equilibrium. The corresponding values seem to be largely exaggerated at the RPA level. For this reason this effect is the dominating one for the whole range of $\mathrm{H} . . . \mathrm{O}$ distances within this approach [13].

Comparing RPA and SOPPA results for system I the following rationalization can be carried out. In Ref.[13], CLOPPA-IPPP decomposition of ${ }^{1} \mathrm{~J}(\mathrm{CH})$ into its $\sigma$ and $\pi$-transmitted components carried out at the RPA level showed that there is a small increase in the $\sigma$ component for decreasing $\mathrm{H} . . . \mathrm{O}$ distances. The $\pi$ component is large and positive and decreases strongly (ca. $10 \mathrm{~Hz}$ ) for H...O distances between infinity and equilibrium. It has been recognized since long time that the $\pi$-transmitted component of triplet response properties in unsaturated compounds can be largely exaggerated at the RPA level. Therefore it can be argued that the reason why SOPPA values of $\Delta \mathrm{J}$ exhibit a different pattern to RPA ones originates in the relative importance of the $\pi$-transmitted component. $\pi$ electrons are more weakly bonded than $\sigma$ ones and exhibit a larger sensitivity to changes in molecular environment. It is thus not surprising that $\Delta \mathrm{J}^{\mathrm{G}}$ on one hand and $\Delta \mathrm{J}^{\mathrm{CG}}$ and $\Delta \mathrm{J}^{\mathrm{EG}}$ on the other behave so differently in system I: the presence of the $\mathrm{H}_{2} \mathrm{O}$ molecule (or electric field) is essential to define the polarization of the electronic $\pi$ system. Such polarization, in turn, affects the $\pi$ component of ${ }^{1} \mathrm{~J}(\mathrm{CH})$ significantly, overcoming the geometric effect. However, this effect is largely exaggerated at the RPA level. In SOPPA values it can be expected that the relative importance of the $\pi$-transmitted component is reduced to a more realistic proportion of the total ${ }^{1} \mathrm{~J}(\mathrm{CH})$ value. This explains the trend found for $\Delta \mathrm{J}^{\mathrm{C}}$ and $\Delta \mathrm{J}^{\mathrm{E}}$ within this approach.

The trend of the relative importance of correlation effects as a function of the H...O distance for systems I and II exhibits interesting features. We define a correlation index (IC):

$$
I C=\left|\frac{J(S O P P A)-J(R P A)}{J(S O P P A)}\right| .100
$$

as a measure of this effect. In figure $7 \mathrm{IC}$ as a function of the $\mathrm{H}$...O distance is presented for ${ }^{1} \mathrm{~J}(\mathrm{CH})$ in systems I and II and the geometric effect on the ${ }^{1} \mathrm{~J}(\mathrm{CH})$ values of the isolated molecules. 


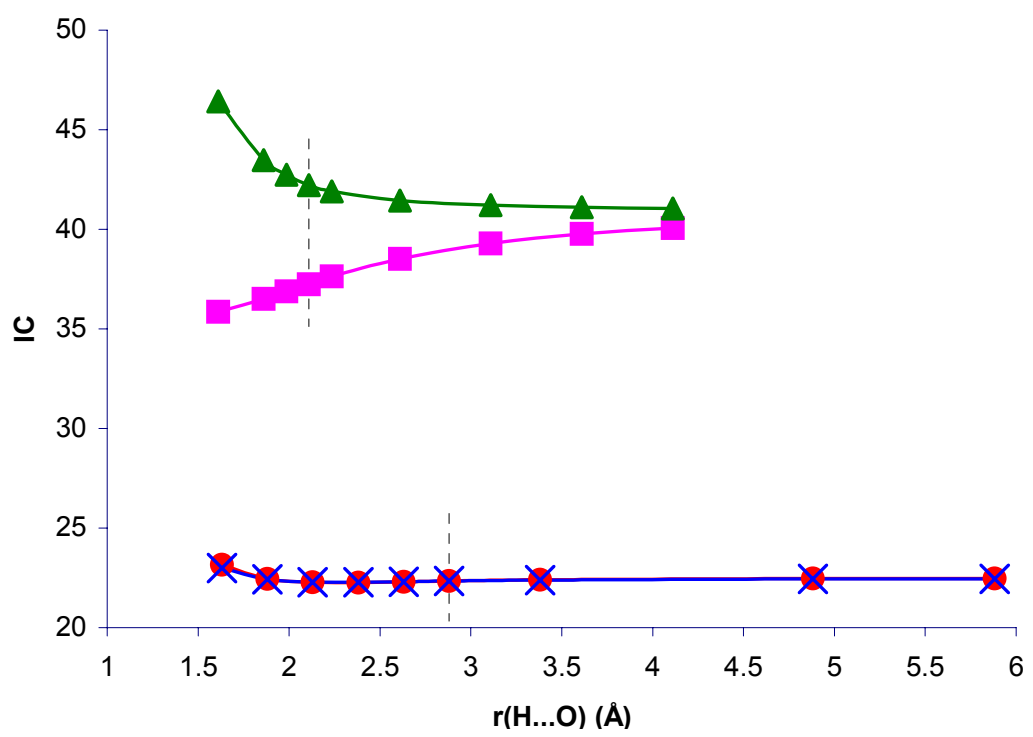

Figure 7. Correlation index for ${ }^{1} \mathrm{~J}(\mathrm{CH}), \mathrm{IC}$, in the $\mathrm{NCH}_{\ldots} . . \mathrm{OH}_{2}$ and $\mathrm{CH}_{4} \ldots \mathrm{OH}_{2}$ complexes, and in the isolated $\mathrm{NCH}$ and $\mathrm{CH}_{4}$ molecules with the complex geometry, as a function of the $\mathrm{H}$... $\mathrm{O}$ distance,

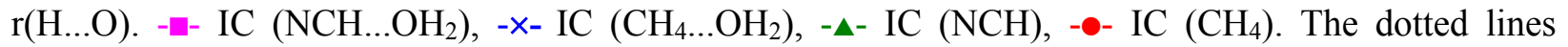
indicate the equilibrium distance in each case.

Correlation effects are very important to define ${ }^{1} \mathrm{~J}(\mathrm{CH})$ in system II, but IC is nearly insensitive to the presence of the $\mathrm{H}_{2} \mathrm{O}$ molecule. It follows closely its geometric component. For system I, the decrease of IC for decreasing $\mathrm{H}$...O distances is remarkable. A similar pattern is found if the $\mathrm{H}_{2} \mathrm{O}$ molecule is replaced by its electric field. When this field is absent, IC increases, i.e., the geometric effect on IC follows the opposite trend. Therefore, the reduction of IC can be ascribed to the polarization of the electronic distribution in the presence of the $\mathrm{H}_{2} \mathrm{O}$ field. This means that there is a coupling mechanism in I which is sensitive to correlation effects and to the mentioned electronic polarization. On one hand, as mentioned earlier, the $\pi$-transmitted component of ${ }^{1} \mathrm{~J}(\mathrm{CH})$ seems to be very sensitive to correlation effects. On the other hand, CLOPPA decomposition of the polarizability tensor has shown quantitatively that $\pi$ electrons are highly polarizable [17]. Therefore it can be speculated that it is the $\pi$-transmitted component which defines the trend of IC in system I. The reduction of IC as a consequence of electron polarization can be rationalized on the following grounds. Polarization of $\pi$ electrons renders the $\pi$ MOs less polarizable. This can be explicitly verified by calculating the polarizability of the $\mathrm{NCH}$ molecule in complex I by means of the IPPP CLOPPA approach. There is a decrease from 21.6 a.u. to 20.5 a.u. It can be expected that electrons occupying less polarizable orbitals will be less sensitive to any type of perturbation, including electron-electron interactions yielding correlation effects on $\mathrm{J}$ couplings. This rationalization is consistent with the observed trend of IC. On the other hand, in system II it can be argued that correlation effects originate in coupling mechanisms involving orbitals which are not affected by polarization of the electronic distribution to the same extent. Therefore in that case IC is not affected by such polarization and it has a similar value for the whole range of H...O distances considered. 


\section{Intermolecular couplings}

The Fermi contact (FC) contribution to intermolecular ${ }^{1 \mathrm{~h}} \mathrm{~J}\left({ }^{1} \mathrm{H}^{17} \mathrm{O}\right)$ and ${ }^{2 \mathrm{~h}} \mathrm{~J}\left({ }^{13} \mathrm{C}^{17} \mathrm{O}\right)$ couplings in systems I and II were calculated at both RPA and SOPPA levels for the respective equilibrium H...O distances. Values thus obtained were negligibly small for both couplings in system II. Values corresponding to system I are displayed in Table 1. The difference in intermolecular couplings in systems I and II can be ascribed to the much longer equilibrium H...O distance in the second case.

Table 1. ${ }^{2 \mathrm{~h}} \mathrm{~J}(\mathrm{CO})$ and ${ }^{1 \mathrm{~h}} \mathrm{~J}(\mathrm{HO})$ in system I calculated within the RPA and SOPPA approximations.

\begin{tabular}{ccc}
\hline & ${ }^{2 \mathrm{~h}} \mathrm{~J}(\mathrm{CO})(\mathrm{Hz})$ & ${ }^{1 \mathrm{~h}} \mathrm{~J}(\mathrm{HO})(\mathrm{Hz})$ \\
\hline FC (RPA) & -13.64 & 6.35 \\
FC (SOPPA) & -10.50 & 3.54 \\
SD (SOPPA) & -0.04 & -0.10 \\
PSO(SOPPA) & 0.06 & 0.67 \\
\hline
\end{tabular}

Intermolecular couplings in system I displayed in Table 1 exhibit interesting features. On one hand, ${ }^{2 \mathrm{~h}} \mathrm{~J}(\mathrm{CO})$ is large, negative and correlation effects are small. The corresponding spin dipolar (SD) and paramagnetic spin orbital (PSO) contributions are negligibly small. On the other hand, ${ }^{1 \mathrm{~h}} \mathrm{~J}(\mathrm{HO})$ is positive and significantly smaller than ${ }^{2 \mathrm{~h}} \mathrm{~J}(\mathrm{CO})$ in absolute value. Correlation effects yield ca. $3 \mathrm{~Hz}$. This is a large correction on a relative scale, but small in absolute value. The corresponding PSO contribution, although small, is significant in a relative scale. It can be concluded that the main differences between ${ }^{2 \mathrm{~h}} \mathrm{~J}(\mathrm{CO})$ and ${ }^{1 \mathrm{~h}} \mathrm{~J}(\mathrm{HO})$ originate in the $\mathrm{FC}$ contribution and its value is reasonably well reproduced at the RPA level. It is interesting to point out that such difference is even larger if reduced couplings are considered, as the gyromagnetic factor of ${ }^{1} \mathrm{H}$ is about four times larger than that of ${ }^{13} \mathrm{C}$. These results are in line with those found by Pecul et al. for the $\mathrm{C}_{2} \mathrm{H}_{2} \ldots \mathrm{H}_{2} \mathrm{O}$ complex [16] Absolute values of intermolecular couplings are smaller in that case. This could be explained by the larger equilibrium H...O distance (2.187 $\AA$ ).

It is interesting to analyze the transmission mechanisms involved in ${ }^{2 \mathrm{~h}} \mathrm{~J}(\mathrm{CO})$ and ${ }^{1 \mathrm{~h}} \mathrm{~J}(\mathrm{HO})$. To this end a CLOPPA decomposition of the FC contribution was carried out at the RPA level in terms of LMOs. The most important two-indices coupling pathways given by every pair of occupied LMOs are presented in Table 2.

It is seen that coupling pathways involving the $\mathrm{C}-\mathrm{H}$ bond and an LMO of the $\mathrm{H}_{2} \mathrm{O}$ molecule yield contributions to both couplings of similar value and opposite signs. Rather unexpectedly, coupling pathways involving only occupied LMOs of the $\mathrm{H}_{2} \mathrm{O}$ molecule yield non-zero contributions only to ${ }^{2 h} \mathrm{~J}(\mathrm{CO})$. As these contributions are also negative, the absolute value of ${ }^{2 \mathrm{~h}} \mathrm{~J}(\mathrm{CO})$ is increased. LMOs describing the $\mathrm{O}$ lone pairs can be classified as follows: one in-plane sp-type LMO, which will be referred to as $1 p \sigma$ and one of pure p-type, which is referred to as $1 p \pi$. As a consequence of the 
Table 2. Main $\mathrm{J}_{\mathrm{ij}}$ coupling pathways (i,j, occupied LMOs) for ${ }^{2 \mathrm{~h}} \mathrm{~J}(\mathrm{CO})$ and ${ }^{1 \mathrm{~h}} \mathrm{~J}(\mathrm{HO})$ in system $\mathrm{I}$.

\begin{tabular}{clcc}
\hline $\mathrm{i}$ & $\mathrm{j}$ & ${ }^{2 \mathrm{~h}} \mathrm{~J}_{\mathrm{ij}}(\mathrm{CO})(\mathrm{Hz})$ & ${ }^{1 \mathrm{~h}} \mathrm{~J}_{\mathrm{ij}}(\mathrm{HO})(\mathrm{Hz})$ \\
\hline $\operatorname{lp} \sigma(\mathrm{O})$ & $\mathrm{C}-\mathrm{H}$ & -6.98 & 5.92 \\
$\operatorname{lp} \sigma(\mathrm{O})$ & $\mathrm{lp} \sigma(\mathrm{O})$ & -1.99 & -0.08 \\
$\operatorname{lp} \sigma(\mathrm{O})$ & $\mathrm{O}-\mathrm{H}_{\mathrm{a}(\mathrm{b})}$ & -1.24 & 0.05 \\
$\mathrm{O}-\mathrm{H}_{\mathrm{a}(\mathrm{b})}$ & $\mathrm{C}-\mathrm{H}$ & -0.59 & 0.53 \\
$\mathrm{C}-\mathrm{H}$ & $\mathrm{C}-\mathrm{H}$ & 0.51 & -0.27 \\
$\Sigma \mathrm{J}_{\mathrm{ij}}$ & & -12.12 & 6.73 \\
\hline
\end{tabular}

attractive interaction yielding a weak hydrogen bond of type C-H...O, the sp-type O lone pair extends towards the $\mathrm{C}$ and $\mathrm{H}$ nuclei. The existence of a contact mechanism involving occupied LMOs of the $\mathrm{H}_{2} \mathrm{O}$ electronic system is thus a direct consequence of this effect. However, a non-zero FC contribution to ${ }^{1 \mathrm{~h}} \mathrm{~J}(\mathrm{HO})$ would also be expected on these grounds. Coupling pathways involving only LMOs of the $\mathrm{NCH}$ environment are all very small.

The reasons of the difference between ${ }^{1 \mathrm{~h}} \mathrm{~J}(\mathrm{HO})$ and ${ }^{2 \mathrm{~h}} \mathrm{~J}(\mathrm{CO})$ must be traced looking at the distribution of vacant LMOs. The set of vacant MOs was localized as explained in section "Method of calculation". Within this classification of vacant LMOs the main four-indices coupling pathways $\mathrm{J}_{\mathrm{ia}, \mathrm{jb}}$ defining ${ }^{1 \mathrm{~h}} \mathrm{~J}(\mathrm{HO})$ and ${ }^{2 \mathrm{~h}} \mathrm{~J}(\mathrm{CO})$ can be obtained. As localization of MOs is not perfect, there are very many terms yielding values of a few Hz. We have looked at those within the local fragment C-H...O. The total sum of coupling pathways involving occupied LMOs C-H, $\mathrm{lp} \sigma(\mathrm{O}), \mathrm{O}-\mathrm{H}_{\mathrm{a}}$ and $\mathrm{O}-\mathrm{H}_{\mathrm{b}}$ (where $\mathrm{H}_{\mathrm{a}}$ and $\mathrm{H}_{\mathrm{b}}$ identify the two $\mathrm{H}$ atoms of the $\mathrm{H}_{2} \mathrm{O}$ molecule) and vacant LMOs C-H*, $\mathrm{s}(\mathrm{O})^{*}, \operatorname{lp} \sigma(\mathrm{O})^{*}, \mathrm{O}-\mathrm{H}_{\mathrm{a}}{ }^{*}$ and $\mathrm{O}-\mathrm{H}_{\mathrm{b}}{ }^{*}$ and $\mathrm{C}-\mathrm{H} . . . \mathrm{O}^{*}$ yields ${ }^{2 \mathrm{~h}} \mathrm{~J}(\mathrm{CO})=-15.45 \mathrm{~Hz}$ and ${ }^{1 \mathrm{~h}} \mathrm{~J}(\mathrm{HO})=5.19 \mathrm{~Hz}$. If the $\mathrm{C}-\mathrm{H} . . . \mathrm{O}^{*}$ vacant LMO is excluded from the sum, results change to ${ }^{2 \mathrm{~h}} \mathrm{~J}(\mathrm{CO})=-4.81 \mathrm{~Hz}$ and ${ }^{1 \mathrm{~h}} \mathrm{~J}(\mathrm{HO})=6.04 \mathrm{~Hz}$. It is thus seen that the C-H...O* LMO yields very important contributions in the first case, but it contributes negligibly small values in the second one. In Table 3 the largest $\mathrm{J}_{\mathrm{ia}, \mathrm{j} b}$ terms within the fragment are displayed in order to identify the main transmission mechanisms involved.

Individual four-indices coupling pathways displayed in Table 3 show the above mentioned trend clearly. Looking at results in Table 3, it must be kept in mind that for given indices i,a,j,b the propagator element $\mathrm{P}_{\mathrm{i} a \mathrm{j} \mathrm{b}}$ is the same for both couplings and therefore the difference in the values of the corresponding coupling pathway $\mathrm{J}_{\mathrm{ia}, \mathrm{jb}}$ depends on the "perturbators" $\mathrm{V}_{\mathrm{ia}}$ and $\mathrm{V}_{\mathrm{jb}}$ at each nucleus. The role of $\mathrm{C}-\mathrm{H} . . . \mathrm{O} *$ in ${ }^{1 \mathrm{~h}} \mathrm{~J}(\mathrm{HO})$ and ${ }^{2 \mathrm{~h}} \mathrm{~J}(\mathrm{CO})$ is quite different. All coupling pathways involving this vacant LMO are negligibly small for ${ }^{1 \mathrm{~h}} \mathrm{~J}(\mathrm{HO})$, but for ${ }^{2 \mathrm{~h}} \mathrm{~J}(\mathrm{CO})$ such terms yield the largest negative values. It can be concluded that $\mathrm{C}-\mathrm{H}$... $\mathrm{O}^{*}$ has sufficiently low energy to make the corresponding propagator elements large enough to couple LMOs from the $\mathrm{NCH}$ and $\mathrm{H}_{2} \mathrm{O}$ environments. The particular shape of this LMO is responsible for the different contributions to both couplings. It is an antibonding like LMO with opposite amplitudes in the $\mathrm{C}-\mathrm{H}$ and $\mathrm{O}$ regions. In particular the corresponding amplitude at the $\mathrm{H}$ nucleus is negligibly small. A coupling pathway of strictly local character is thus found which is 
Table 3. Main "coupling pathways" $\mathrm{J}_{\mathrm{ia}, \mathrm{jb}}$ involving the $\mathrm{C}-\mathrm{H}$ and $\operatorname{lp} \sigma(\mathrm{O})$ occupied LMOs and vacant LMOs within the local fragment C-H...O in system I. Values in Hz.

\begin{tabular}{|c|c|c|c|c|c|}
\hline $\mathrm{i}$ & $\mathrm{j}$ & $\mathrm{a}$ & $\mathrm{b}$ & ${ }^{2 \mathrm{~h}_{\mathrm{ia}, \mathrm{b}}}(\mathrm{CO})$ & ${ }^{1 \mathrm{~h}} \mathrm{~J}_{\mathrm{ia}, \mathrm{j} b}(\mathrm{HO})$ \\
\hline \multirow[t]{6}{*}{$\operatorname{lp} \sigma(O)$} & $\operatorname{lp} \sigma(O)$ & СH... $\mathrm{O}^{*}$ & СН... ${ }^{*}$ & -7.74 & -0.03 \\
\hline & & $\mathrm{s}(\mathrm{O})^{*}$ & CH...O* & 3.81 & 0.01 \\
\hline & & $\mathrm{O}-\mathrm{H}^{*}$ & $\mathrm{O}-\mathrm{H}^{*}$ & 3.77 & 4.68 \\
\hline & & $\operatorname{lp} \sigma(O)^{*}$ & $\operatorname{lp} \sigma(\mathrm{O})^{*}$ & -3.37 & -1.91 \\
\hline & & C-H* & $\mathrm{O}-\mathrm{H}^{*}$ & -1.66 & -5.13 \\
\hline & & $\mathrm{s}(\mathrm{O})^{*}$ & $\mathrm{O}-\mathrm{H}^{*}$ & -1.53 & -2.53 \\
\hline \multirow[t]{6}{*}{$\operatorname{lp} \sigma(O)$} & $\mathrm{C}-\mathrm{H}$ & СН... ${ }^{*}$ & СН... ${ }^{*}$ & -4.93 & -0.04 \\
\hline & & $\mathrm{O}-\mathrm{H}^{*}$ & CH...O* & -3.48 & -0.03 \\
\hline & & $\mathrm{s}(\mathrm{O})^{*}$ & C-H & 3.05 & -4.43 \\
\hline & & $\operatorname{lp} \sigma(\mathrm{O})^{*}$ & СH... ${ }^{*}$ & 2.71 & 0.02 \\
\hline & & $\operatorname{lp} \sigma(\mathrm{O})^{*}$ & $\mathrm{C}-\mathrm{H}^{*}$ & -2.59 & 7.84 \\
\hline & & $\mathrm{O}-\mathrm{H}^{*}$ & $\mathrm{O}-\mathrm{H}$ & 2.21 & 5.65 \\
\hline
\end{tabular}

operative in $\mathrm{C}-\mathrm{H}$...O interactions and is very efficient for ${ }^{2 \mathrm{~h}} \mathrm{~J}(\mathrm{CO})$ but does not contribute to ${ }^{1 \mathrm{~h}} \mathrm{~J}(\mathrm{HO})$. The argument is valid for the reduced coupling constants, and it explains the larger absolute value of ${ }^{2 \mathrm{~h}} \mathrm{~K}(\mathrm{CO})$ than ${ }^{1 \mathrm{~h}} \mathrm{~K}(\mathrm{HO})$. Coupling pathways involving the $\mathrm{C}-\mathrm{H} \rightarrow \mathrm{C}-\mathrm{H}^{*}$ excitation yield contributions of opposite signs to both couplings. This can be directly ascribed to the general fact that the bonding and antibonding LMOs have opposite relative phases at the $\mathrm{C}$ and $\mathrm{H}$ nuclei. As the second excitation to both couplings entering a given coupling pathway $\mathrm{J}_{\mathrm{i} a \mathrm{j} \mathrm{b}}$ is centered at the $\mathrm{O}$ nucleus, the corresponding values necessarily carry opposite signs. This kind of coupling pathway is the one usually found when a through-space mechanism operates. In fact the leading contribution to ${ }^{1 \mathrm{~h}} \mathrm{~J}(\mathrm{HO})$ is of this type. The corresponding value is positive for this coupling and negative for ${ }^{2 \mathrm{~h}} \mathrm{~J}(\mathrm{CO})$.

\section{Concluding Remarks}

Identification of transmission mechanisms of $\mathrm{J}$ couplings in terms of local fragments of the electronic distribution is a valuable tool to analyze their behavior in different molecular environments. Correlated results found in this work for ${ }^{1} \mathrm{~J}(\mathrm{CH})$ in systems I and II complement previous findings $[13,15]$ with new interesting qualitative features which are related to the expected behavior of the $\pi$ transmitted component of the FC term. CLOPPA decomposition of intermolecular couplings ${ }^{1 \mathrm{~h}} \mathrm{~J}(\mathrm{HO})$ and ${ }^{2 h} \mathrm{~J}(\mathrm{CO})$ led to an explanation of the larger absolute value of the (reduced) coupling in the second case in terms of LMOs within the local C-H...O fragment. In particular a vacant LMO of the C-H...O* type was shown to play an important role in defining such difference. It would be interesting to verify the role played by such mechanisms in different X-H...O moieties in order to analyze the generality of the obtained results. Work along this line is under progress in our group. 


\section{Acknowledgments}

Financial support from UBACYT and CONICET is gratefully acknowledged. We would like to thank Prof. P. Lazzeretti for providing us a copy of the SYSMO program.

\section{References and Notes}

1. Del Bene, J. E.; Perera, S. A.; Bartlett, R. J.; Elguero, J.; Alkorta, I.; Lopez-Leonardo, C.; Alajarin, M. J. Am. Chem. Soc. 2002, 124, 6393-6397.

2. Barfield, M. J. Am. Chem. Soc. 2002, 124, 4158-4168.

3. Pecul, M.; Sadlej, J.; Leszczynski J. J. Chem. Phys. 2001, 115, 5498-5506.

4. Barfield, M.; Bergset, J. M.; O’Leary, D. J. Magn. Reson. Chem. 2001, 39, S115-S125.

5. Chapman, K.; Crittenden, D.; Bevitt, J.; Jordan, M. J. T.; Del Bene, J. E. J. Phys. Chem. A 2001, $105,5442-5449$.

6. Barfield, M.; Dingley, A. J.; Feigon, J.; Grzesiek, S. J. Am. Chem. Soc. 2001, 123, 4014-4022.

7. Del Bene, J. E.; Perera, S. A.; Bartlett, R. J. J. Phys. Chem. A 2001, 105, 930-934.

8. Pecul, M.; Leszczynski, J.; Sadlej, J. J. Phys. Chem. A 2000, 104, 8105.

9. Bagno, A. Chem. Eur. J. 2000, 6, 2925-2930.

10. Specialist Periodical Report: Nuclear Magnetic Resonance, Royal Society of Chemistry, London, vol. 29, 2000, vol. 30, 2001 and vol. 31, 2002.

11. Green, R. D., Hydrogen Bonding by C-H Groups, Mcmillan, London, 1974.

12. Jeffrey, A., Hydrogen Bonding in Biological Structures, Springer, Berlin, 1991.

13. Giribet, C. G.; Vizioli, C. V.; Ruiz de Azúa, M. C.; Contreras, R. H.; Dannenberg, J. J.;Masunov, A. J. Chem. Soc., Faraday Trans. 1996, 92, 3029-3033.

14. Peralta, J. E.; Ruiz de Azúa, M. C.; Contreras, R. H. J. Mol. Struct. (THEOCHEM) 1999, 491, 2331.

15. Vizioli, C.; Ruiz de Azúa, M. C.; Giribet, C. G.; Contreras, R. H.; Turi, L.; Dannenberg, J. J.; Rae, I. D.; Weigold, J. A.; Malagoli, M.; Zanasi, R.; Lazzeretti, P. J. Phys. Chem. 1994, 98, 8858-8861.

16. Pecul, M.; Leszczynski, J.; Sadlej, J. J. Chem. Phys. 2000, 112, 7930-7938.

17. Giribet, C. G.; Demarco, Ma. D.; Ruiz de Azúa, M. C.; Contreras, R. H. Molec. Phys. 1997, 91, 105-111.

18. Jørgensen, P.; Simons, J. Second Quantization-based Methods in Quantum Chemistry, Academic Press, London, 1981.

19. Engelmann, A. R.; Contreras, R. H. Int. J. Quantum Chem. 1983, 23, 1033-1045.

20. Ruiz de Azúa, M. C.; Diz. A. C.; Giribet, C. G.; Contreras, R. H.; Rae, I. D. Int. J. Quantum Chem. 1986, S20, 585-601.

21. Diz, A. C.; Giribet, C. G.; Ruiz de Azúa, M. C.; Contreras, R. H. Int. J. Quantum Chem. 1990, 37, 663-677.

22. Geertsen, J.; Oddershede, J. Chem. Phys. 1984, 90, 301.

23. Enevoldsen T.; Oddershede, J.; Sauer, S. P. A. Theor. Chem. Acc. 1998, 100, 275-284. 
24. Gaussian 98, Revision A.7: Frisch, M. J.; Trucks, G. W.; Schlegel, H. B.; Scuseria, G. E.; Robb, M. A.; Cheeseman, J. R.; Zakrzewski, V. G.; Montgomery, J. A.; Stratmann, R. E., Jr.; Burant, J. C.; Dapprich, S.; Millam, J. M.; Daniels, A. D.; Kudin, K. N.; Strain, M. C.; Farkas, O.; Tomasi, J.; Barone, V.; Cossi, M.; Cammi, R.; Mennucci, B.; Pomelli, C.; Adamo, C.; Clifford, S.; Ochterski, J.; Petersson, G. A.; Ayala, P. Y.; Cui, Q.; Morokuma, K.; Malick, D. K.; Rabuck, A. D.; Raghavachari, K.; Foresman, J. B.; Cioslowski, J.; Ortiz, J. V.; Baboul, A. G.; Stefanov, B. B.; Liu, G.; Liashenko, A.; Piskorz, P.; Komaromi, I.; Gomperts, R.; Martin, R. L.; Fox, D. J.; Keith, T.; Al-Laham, M. A.; Peng, C. Y.; Nanayakkara, A.; Gonzalez, C.; Challacombe, M.; Gill, P. M. W.; Johnson, B.; Chen, W.; Wong, M. W.; Andres, J. L., Gonzalez, C.; Head-Gordon, M.; Replogle, E. S.; Pople, J. A.; Gaussian, Inc.: Pittsburgh PA, 1998.

25. Lazzeretti, P.; Zanasi, R. J. Chem. Phys. 1982, 77, 2448-2453.

26. Lazzeretti, P. Int. J. Quantum Chem. 1979, 15,181.

27. Lazzeretti P. J. Chem. Phys. 1979, 71, 2514-2521.

28. DALTON, a Molecular Electronic Structure Program, Release 1.2 (2001), written by T. Helgaker, H.J.Aa. Jensen, P. Jørgensen, J. Olsen, K. Ruud, H. Ågren, A.A. Auer, K.L. Bak, V. Bakken, O. Christiansen, S. Coriani, P. Dahle, E.K. Dalskov, T. Enevoldsen, B. Fernandez, C. Hättig, K. Hald, A. Halkier, H. Heiberg, H. Hettema, D. Jonsson, S. Kirpekar, R. Kobayashi, H. Koch, K.V. Mikkelsen, P. Norman, M.J. Packer, T.B. Pedersen, T.A. Ruden, A. Sanchez, T. Saue, S.P.A. Sauer, B. Schimmelpfennig, K. O. Sylvester-Hvid, P.R. Taylor, and O. Vahtras.

29. Van Duijneveldt, F. B., IBM Res. Rep. 1971, RJ 945.

(C) 2003 by MDPI (http://www.mdpi.org). Reproduction for noncommercial purposes permitted. 